\title{
Analysis of the Factors on Intrauterine Insemination (IUI) Results by Clustering
}

\section{A R T I C L E I N F O}

\section{Article Type}

Original research

\section{Authors}

Alizadeh S. ${ }^{1} \mathrm{PhD}$

Asghari M.* $M S c$,

Hosseini M.K. ${ }^{1} M S C$

\section{How to cite this article}

Alizadeh S, Asghari M, Hosseini M

$\mathrm{K}$. Analysis of the Factors on

Intrauterine Insemination (IUI)

Results by Clustering. Sarem Jo-

urnal of Reproductive Medicine.

2017;1(3):105-112.
*Information Technology Department, Computer Engineering Faculty, K. N. Toosi University of Technology, Tehran, Iran

${ }^{1}$ Information Technology Department, Computer Engineering Faculty, K. N. Toosi University of Technology, Tehran, Iran

\section{Correspondence}

Address: -

Phone: -

Fax: -

mohsen.asghari@gmail.com

\section{Article History}

Received: February 26, 2016

Accepted: June 21,2016

ePublished: August 15, 2017

\begin{abstract}
A B S T R A C T
Aims Intra Uterine Insemination (IUI) is a medically-assisted reproduction technique (ART) enables infertile couples to achieve the successful pregnancy. Given the unpredictability of such techniques, many investigations have been done on the factors affecting the techniques. Data mining is one of the main tools that can help researchers to evaluate the factors. Data mining utilize the statistical methods along with the artificial intelligence (AI) to help different sciences including infertility science and research for interpreting the results and analyzes of data appropriately and extracting the hidden patterns and knowledge in the data. The objective of this study was to analyze the factors affecting IUI results by clustering.

Materials \& Methods The IUI data were clustered utilizing the K-means Ja clustering method in data mining). Davise-Buldian index was used to calculate the best number of clusters. The similar individuals were included in the same cluster and the success rates in those clusters were also measured.

Findings Some of the characteristics of individuals such as age, body mass index (BMI), type of infertility, the cause of infertility and etc. were effective factors on IUI success rate.

Conclusion Factors such as age, BMI, type of infertility, the cause of infertility and etc. can determine the success rate of the IUI method.
\end{abstract}

Keywords Infertility; Insemination, Artificial; Clustering; Data Mining

\section{CIT A T I O N L I N KS}

[1] Data Mining Curriculum: A Proposal (Version 1.0) [2] Diabetes-like renal glomerular disease in Fanconi-Bickel syndrome [3] Data Mining: Concepts and Techniques [4] Infertility Guideline [5] Fertility outcome after IVF and related factors [6] Bayesian classification for the selection of in vitro human embryos using morphological and clinical data [7] The relationship between number of transferred embryos and pregnancy rate in ART cycles [8] Data Mining and Knowledge Discovery [9] Sodium butyrate activates erythroid-specific 5-aminolevulinate synthase gene through Sp1 elements at its promoter [10] A comparison in cluster validation techniques [11] Data Mining: Practical Machine Learning Tools and Techniques [12] Integrating genetic algorithm and decision tree learning for assistance in predicting in vitro fertilization outcomes [13] Case-based reasoning in IVF: Prediction and knowledge mining [14] Factors predicting the cumulative outcome of IVF/ICSI treatment: A multivariable analysis of 2450 patients 
ييشبينى رفتارهاى آينده آنها استفاده مىشود. از رايجترين

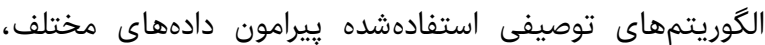

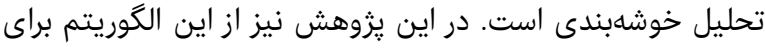

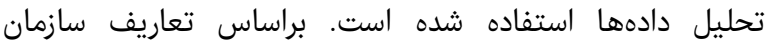

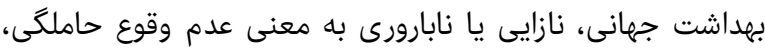

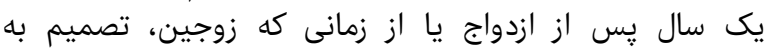

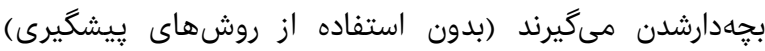

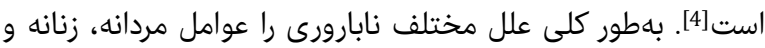

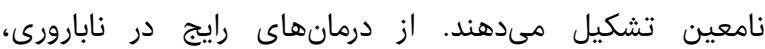

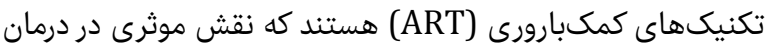

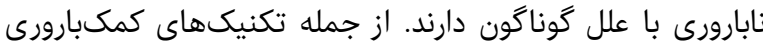

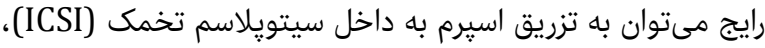

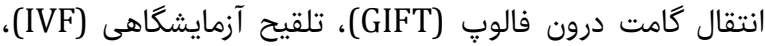
تلقيح درون رحمى (IUI) و انتقال تخم درون فالوپ آلقائ (ZIFT)

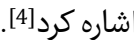

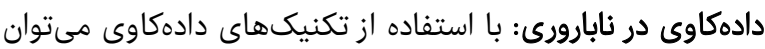

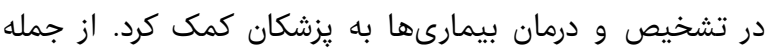

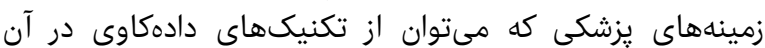

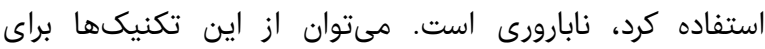

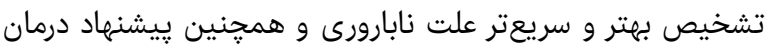

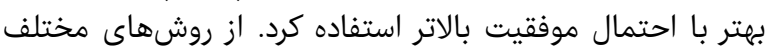

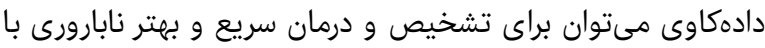

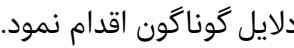

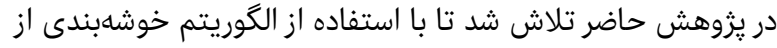

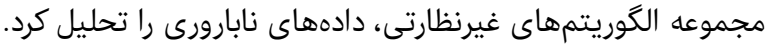

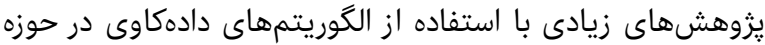

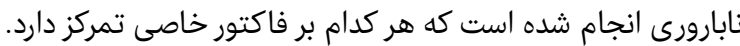

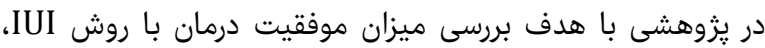

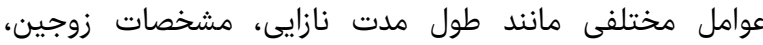

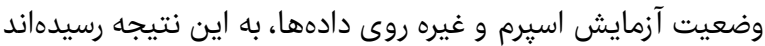

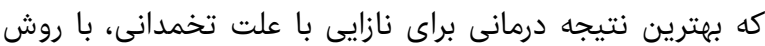
IUI به دست مي آيد]5]

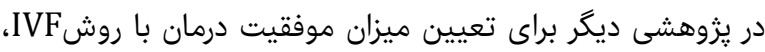

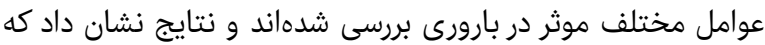

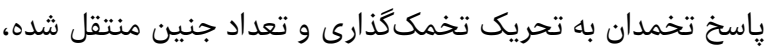

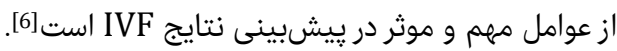

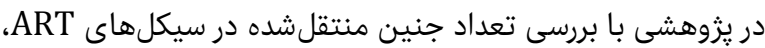

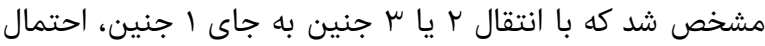

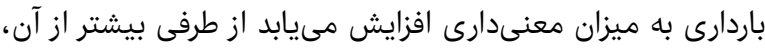

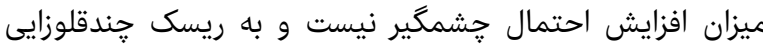

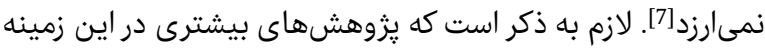

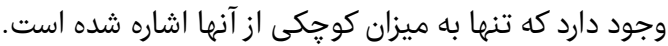

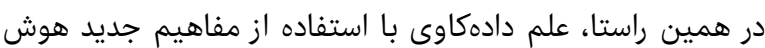

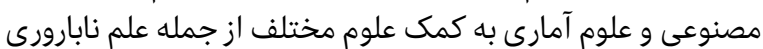

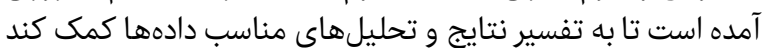

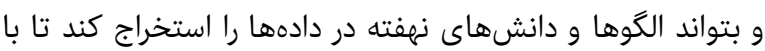

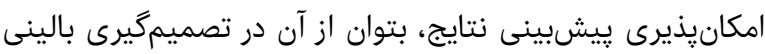

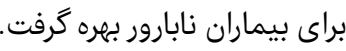
اين مطالعه با هدف تحليل عوارئ برامل موثر بران بر نتايج روش انتقال داخلرحمى اسيرم با استفاده از خوشهبندى انجام شد.

\section{تحليل عوامل موثر بر نتايج روش انتقال

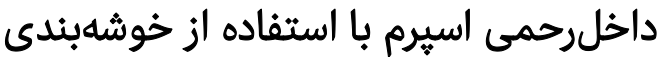

سميه عليزاده PhD كروه فناورى اطلاعات، دانشكده مهندسى كامييوتر، دانشكاه خواجه نصيرالدين طوسى، تهران، ايران MSc" محسن اصغرى نمران، كروه فناورى اطلاعات، دانشكده مهندسى كامييوتر، دانشكاه خواجه نصيرالدين طوسى، تهران، ايران

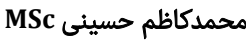
كروه فناورى اطلاعات، دانشكده مهندسى كاميِيوتر، دانشكاه خواجه نصيرالدين

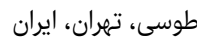

جكيده

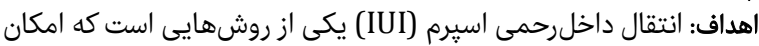

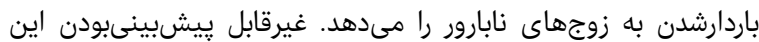

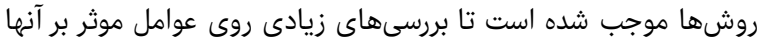

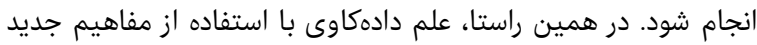

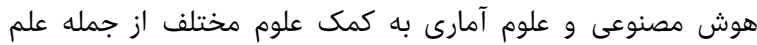

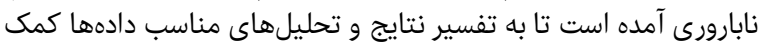

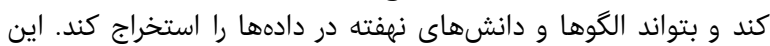

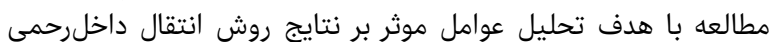

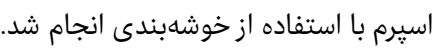

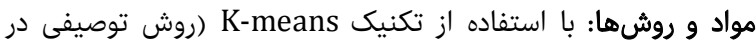

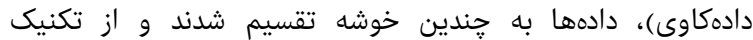

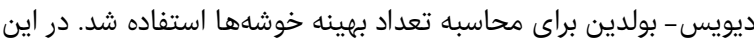

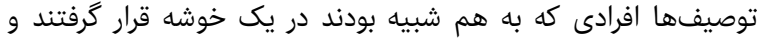

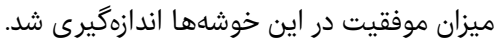

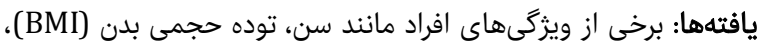

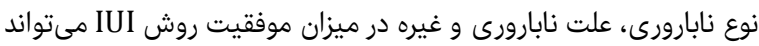

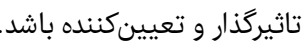

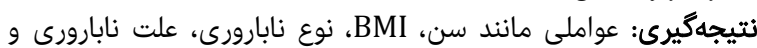

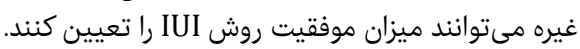

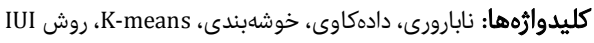

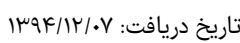

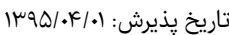
mohsen.asghari@gmail.com :تويسنده مسئول:

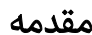

امروزه يِيشرفت روزافزون علوم مختلف در زمينه فناورى اطلاعات،

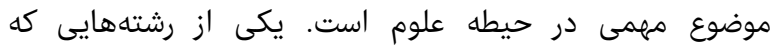

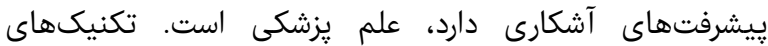

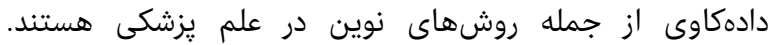

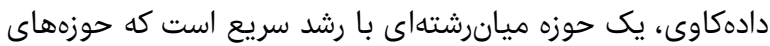

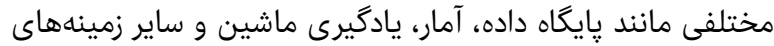

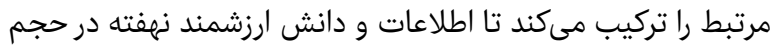

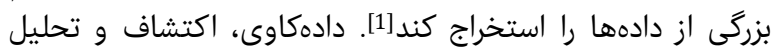

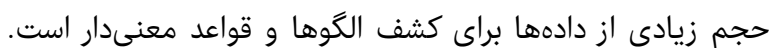

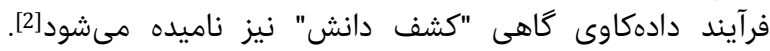

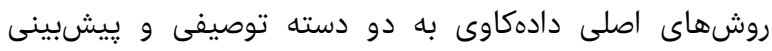

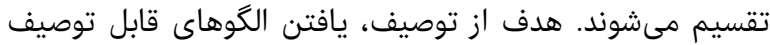

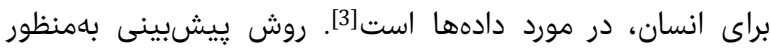




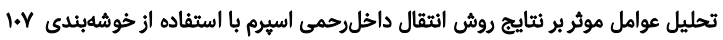

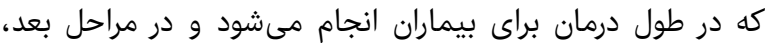

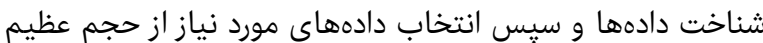

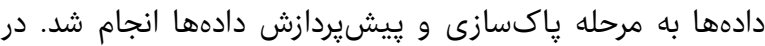

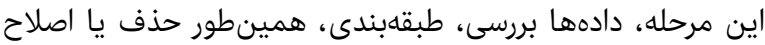

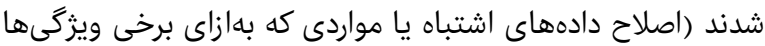

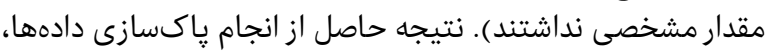

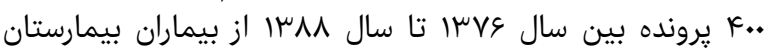

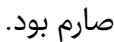

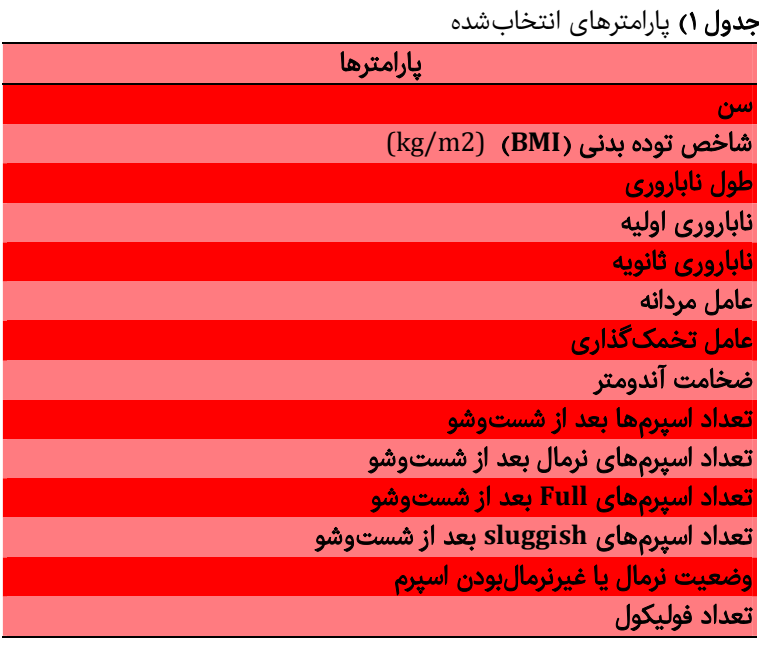

در مرحله بعدى، مدل خوشهبندى انتخاب شده روى نمونه آمارى آداى

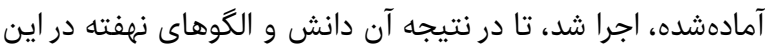
دادهها استخراج شود.

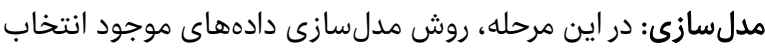

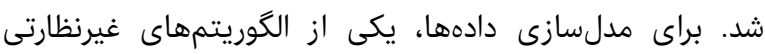

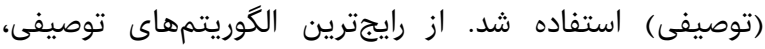

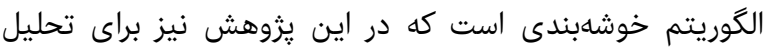

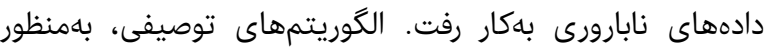
كشف الخوهاى مشابه بين دستههاى مختلف دادئ دادهاريا استفادها

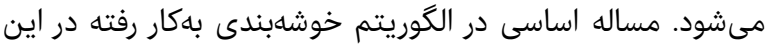

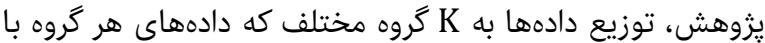

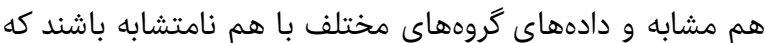

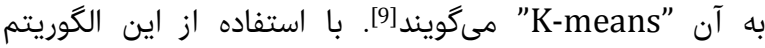

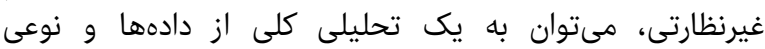

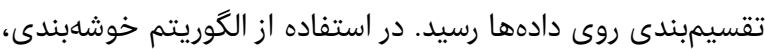

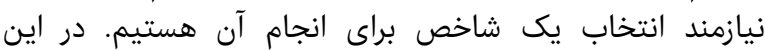

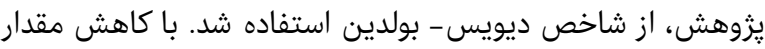

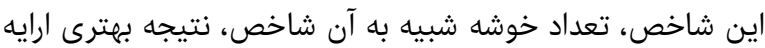

براى رسيدن به تحليل مناسب و تفسير بهتر نتايج، جندينبار

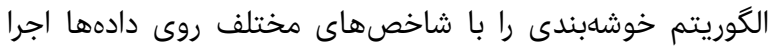

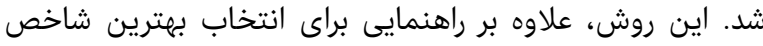

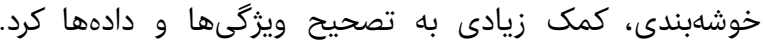

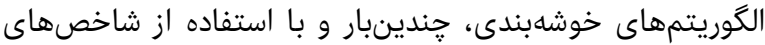

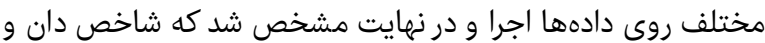

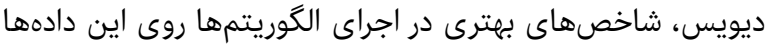

اين مطالعه براساس مدل شناختهشده فرآيند استاندارد صنعت[8]

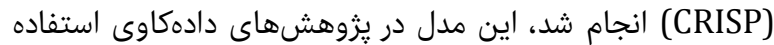

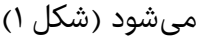

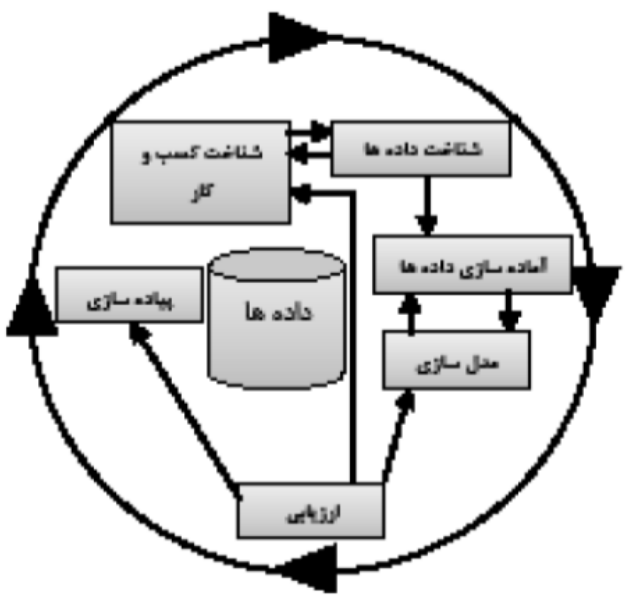

شكل 1) روششناسى CRISP

فرآيندهايى كه براساس اين روش، در اين يُوهش دنبال شد،

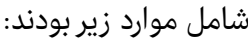

شناخت كسب و كار: در اين گام از تحليل، فرآيندهاى موجود مرد در

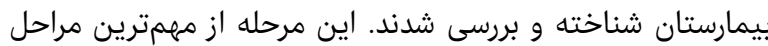

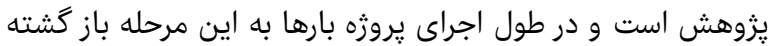

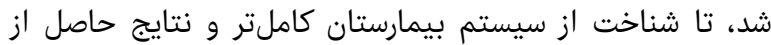
دادمكاوى را با آن ارزيابى شد. شئ.

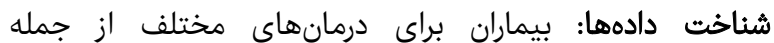
هي و ZIFT ، GIFT ،IUI ،ICSI

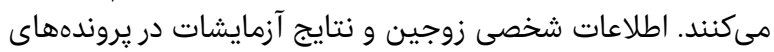

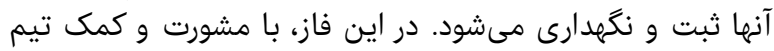

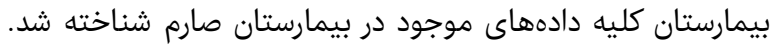

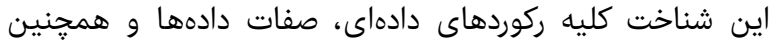
آشنايى با مفاهيم انواع روشهاى دردين درمانى (شامل انواع آزمايشات)، را دربرمىگيرد.

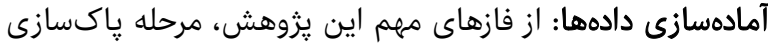

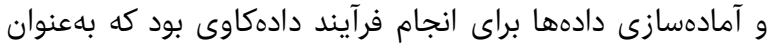

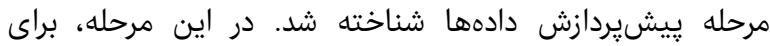

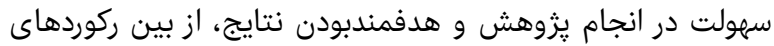

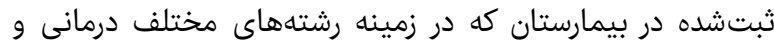

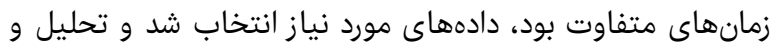

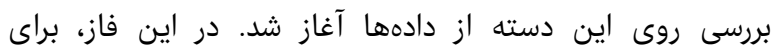

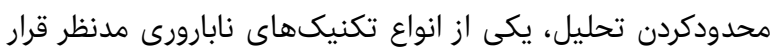

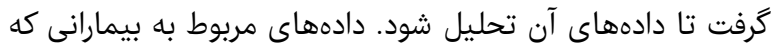

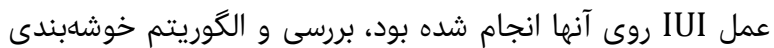

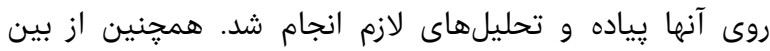

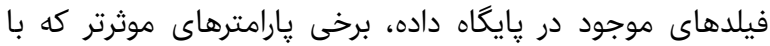

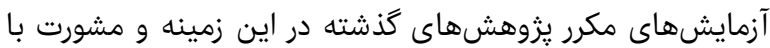

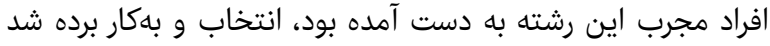

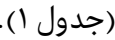
يس از مرحله شناخت سيستم بيمارستان و آشنايى با فرآيندهايى 
انتخاب تعداد خوشه بهينه: با آنجه در مورد فرمولهاى اين دو دوات دران

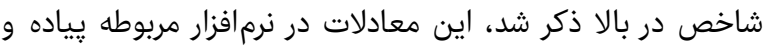

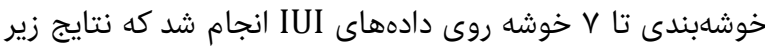

را در برداشت.

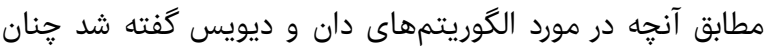

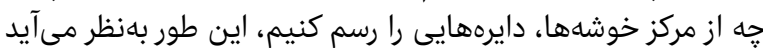

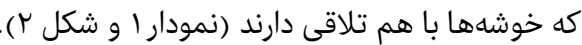

\section{مقايسه شاخص ها}

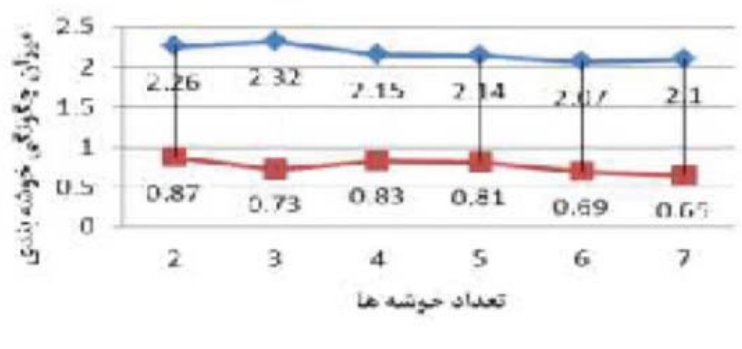

$\rightarrow$ Dun $\rightarrow$ Dawise Bouldiar

نمودار 1) مقايسه شاخص دان و ديويس

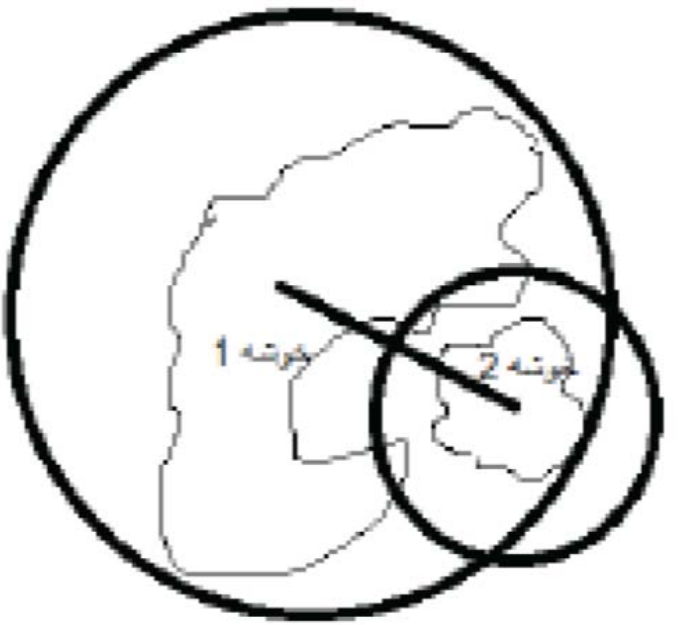

شكل r) تلاقى خوشهها

از اين رو شاخص دان نتيجه مناسبى را براى اين خوشهبندى ارايه

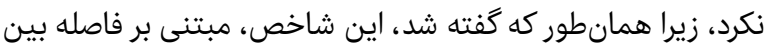

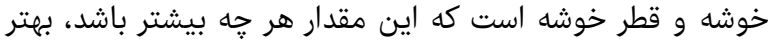

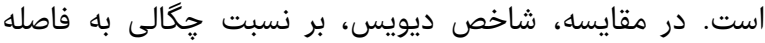

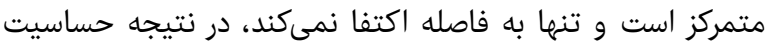

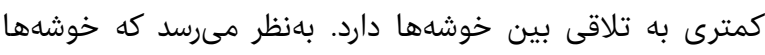

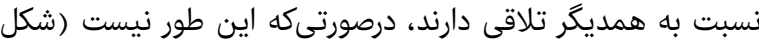

. (

با درنظر گرفتن تعداد بهينهاى كه هريك از اين شاخصها نشان

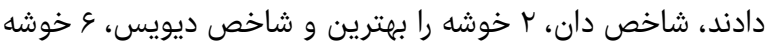

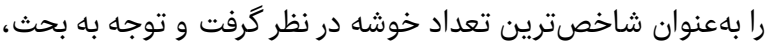

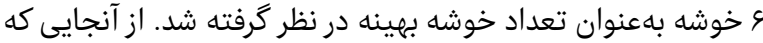

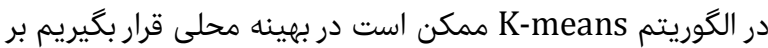
آن شديم تا از الكوريتم ديكرى به نام استفاده كنيم[11] تا از نتيجه حاصل نامل از الكوري الكوريتم K-means و شاخص DB مطمئن شويم. نتايج حاصل از اجراى

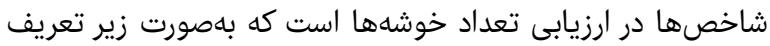
مى شود: - معاده معادله 1.

$$
V(\delta)=\frac{\min _{h} k=1, \ldots K d_{c}\left(C_{k}, C_{h}\right)}{\max k=1, \ldots k \Delta\left(C_{k}\right)}
$$

در معادله ا، عبارت d فاصله بين دو خوشه k و h محاسبه مىكند كه در صورت فرمول قرار دارد و عبارت

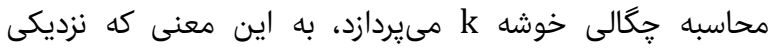

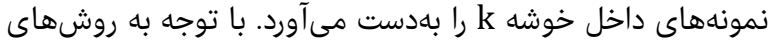

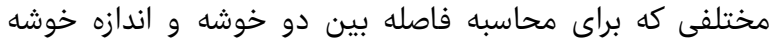

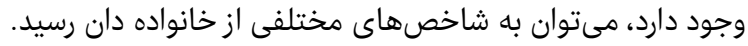

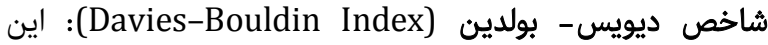

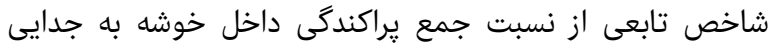

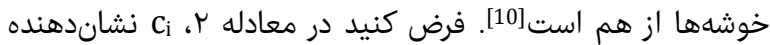

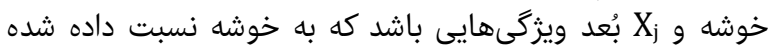

معادله r

$$
S_{i}=\sqrt[q]{\frac{1}{T_{i}} \sum_{j=1}^{T_{i}}\left|X_{j}-A_{i}\right|^{q}}
$$

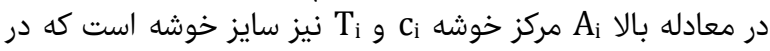

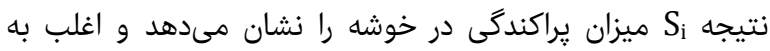

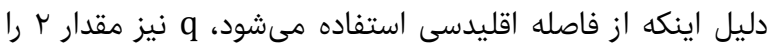

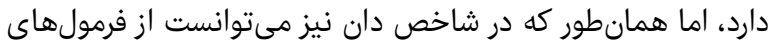

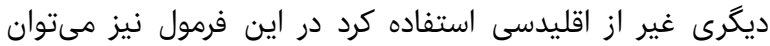
استفاده كرد: معادله س.

$$
S_{i}=\sqrt[q]{\frac{1}{T_{i}} \sum_{j=1}^{T_{i}}\left|X_{j}-A_{i}\right|^{q}}
$$

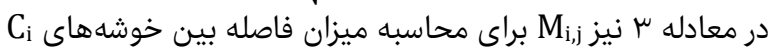

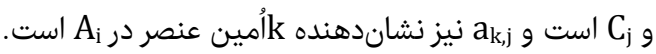

$$
S_{i}=\sqrt[q]{\frac{1}{T_{i}} \sum_{j=1}^{T_{i}}\left|X_{j}-A_{i}\right|^{q}}
$$

معادله F.

در معادله F نيز Ri, ميزانى است كه مشخص مىكند خوشه جقدر

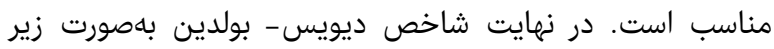
تعريف مى شود: معادله ه.

$$
S_{i}=\sqrt[q]{\frac{1}{T_{i}} \sum_{j=1}^{T_{i}}\left|X_{j}-A_{i}\right|^{q}}
$$

با توجه به معادله ه صورت فرمول مربوطه، نشاندهنده جگًالبودن

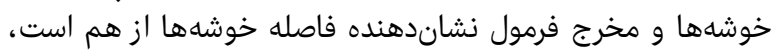

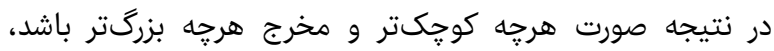
مطلوبتر خواهد بود. يس مقدار DB هرجه كمتر باشد، مطلوبت هرجتر 
تحليل عوامل موثر بر نتايج روش انتقال داخلرحمى اسيرم با استفاده ازخوشهبندى 1.9

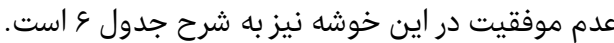

جدول ارزش خارامتر در خوشه

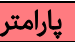

\begin{tabular}{|c|c|}
\hline$\%$ & عامل تخمكگذارى \\
\hline$\% १ \% \%$ & عامل مردانه \\
\hline 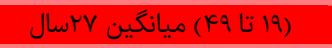 & سن \\
\hline$\% \mu /$ & $\mathrm{BMI}<\mathrm{M} / \mathrm{Q}$ \\
\hline$\%$ \% $/$. & $|\mathrm{A} / \mathrm{Q}<\mathrm{BM}|<r F / Q$ \\
\hline$\% \mu r / \cdot$ & $r \Delta<B M I<r q / q$ \\
\hline$\% \mid \vee /$. & BMI $>\mu$. \\
\hline (ا تا \&l) ميانكين \&/هسال & 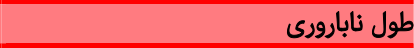 \\
\hline$\% \mid .$. & نابارورى اوليه \\
\hline$\cdot$ & 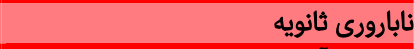 \\
\hline 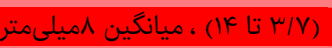 & ضخامت آندومتر \\
\hline 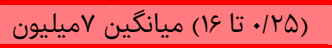 & تعداد اسيرم بعد از شستوشو \\
\hline 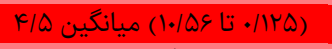 & تعداد اسيرمهاى نرمال بعد از شستوشو | \\
\hline 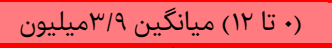 & تعداد اسيرمهاى FULL بعد از شستوشو \\
\hline 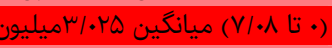 & تعداد اسيرمهاى كند بعد از شستوشو \\
\hline$\% \wedge \kappa / k$ & Terato Spermia \\
\hline$\% \mu / 1$ & Asterato Spermia \\
\hline$\% 11 / \mathrm{V}$ & Pyo spermia \\
\hline$\% \cdot / 1$ & Spermogram Normal \\
\hline
\end{tabular}

جدول \&) نتايج خوشه اول (\%)

\begin{tabular}{|c|c|}
\hline ارزش پارامتر در خوشه & ڤيارامتر \\
\hline$\Lambda \cdot / 1$ & عدم موفقيت \\
\hline $10 / \mu$ & موفقيت \\
\hline F/\& & نامشخص \\
\hline
\end{tabular}

جدول ه) نتايج حاصل از خوشه دوم

\begin{tabular}{|c|c|}
\hline ارزش بارامتر در خوشه & يارامتر \\
\hline$\cdot$ & عامل تخمكگذارى \\
\hline$\% १ \% / \wedge$ & عامل مردانه \\
\hline 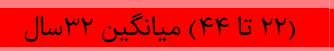 & سن \\
\hline$\cdot$ & $\mathrm{BMI}<1 \mathrm{~N} / \mathrm{Q}$ \\
\hline$\% \vee \backslash / 9$ & $\mid A / Q<B M I<r F / 9$ \\
\hline - & $r \Delta<B M I<r q / q$ \\
\hline$\% \curlyvee \wedge / 1$ & BMI $>\mu$ 。 \\
\hline (ه/• تا r|) ميانكين V/rاسال & طول نابارورى \\
\hline$\cdot$ & ن - ابارورى اوليه \\
\hline$\% 1 .$. & نابارورى ثانويه \\
\hline (ه تا (I) ميانكين Vميلىمتر & ضخامت آندومتر \\
\hline 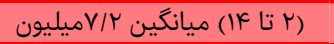 & تعداد اسيرم بعد از شستوشو \\
\hline ( ا تا 9/9) ميانكين \&/F/ميليون & تعداد اسيرمهاى نرمال بعد از شستوشو \\
\hline 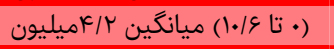 & تعداد اسيرمهاى FULL بعد از شستوشو \\
\hline 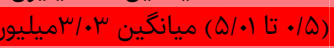 & تعداد اسيرمهاى كند بعد از شستوشو \\
\hline$\% 1 .$. & Terato Spermia \\
\hline
\end{tabular}

جدول \&) نتايج خوشه دوم (\%)

\begin{tabular}{|c|c|}
\hline ارزش خارامتر در خوشه & يارامتر \\
\hline $9 . / V$ & عدم موفقيت \\
\hline$q / \mu$ & موفقيت \\
\hline • & نامشخص \\
\hline
\end{tabular}

نتايج بهدستآمده از خوشه سوم نيز به شرح جدول V است و نتايج موفقيت و عدم موفقيت در جدول ^ آورده شده است.
الكَوريتم EM نيز \& خوشه را به ما ارايه كرد. در اين الكوريتم به

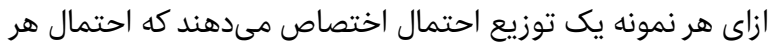

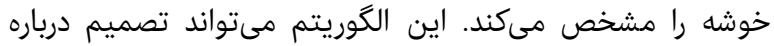

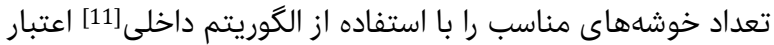

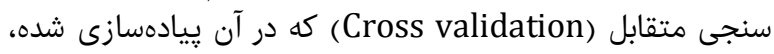

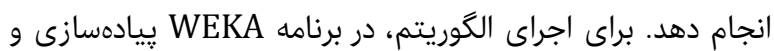

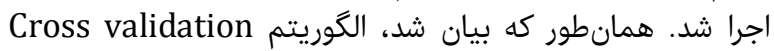

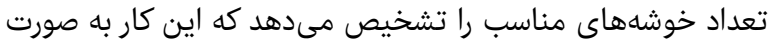

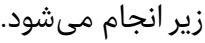

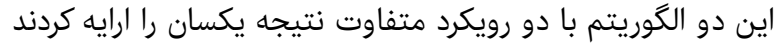

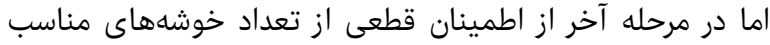

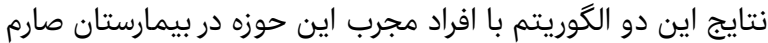

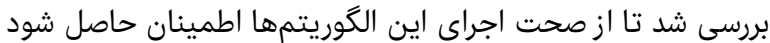

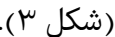

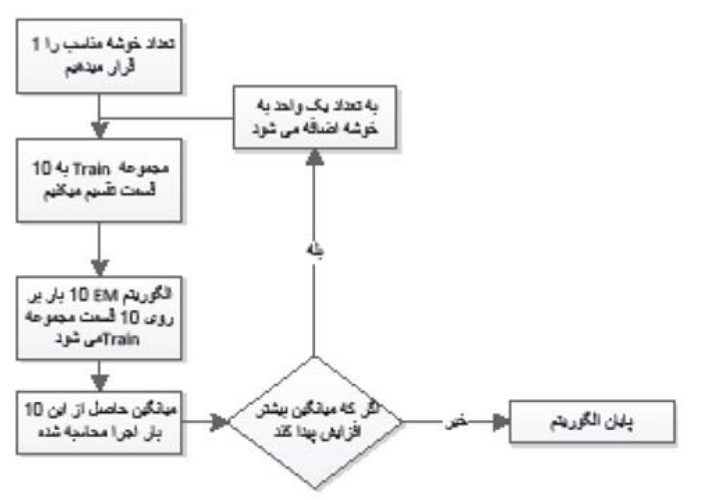

شكل س) روند محاسبه تعداد خوشه مناسب در الكوريتم EM

يافتهها

يس از V بار اجراى الكوريتم K-means كه براى خوشهبندى روى

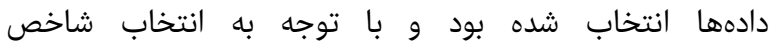

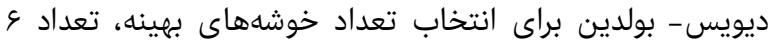

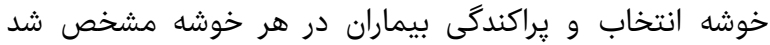

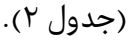

جدول r) يراكندگى بيماران در هر خوشه

\begin{tabular}{|c|c|c|c|c|}
\hline 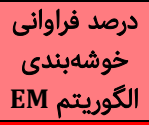 & درصد فراوانى & $\begin{array}{c}\text { فراوانى در } \\
\text { EM }\end{array}$ & $\begin{array}{c}\text { دراوانى } \\
\text { K-means }\end{array}$ & اسم خوشه \\
\hline$\mu q$ & $\mu r$ & $10 \mathrm{~V}$ & IrA & خوشه | \\
\hline$\wedge$ & $\wedge$ & $\mu$. & $\mu r$ & خوشه r \\
\hline Ir & $1 \pi$ & kV & $\Delta r$ & خوشه س \\
\hline$\mu$ & v & I & rV & خوشه F \\
\hline$r$. & $r \mu$ & 11 & 91 & خوشه هـ \\
\hline 11 & IV & Vr & v. & خوشه \& \\
\hline
\end{tabular}

در ادامه هركدام از \& خوشه انتخابشده، تحليل شدهاند.

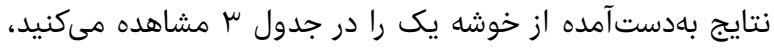

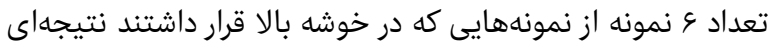

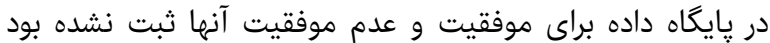

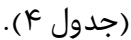
نتايج بهدست آمده از خوشه دوم نيز در جدول ه و نتايج موفقيت و 
نتايج بهدستآمده از خوشه ينجم نيز به شرح جدول لر است همجنين نتايج موفقيت و عدم موفقيت در اين خوشه نيز نيز به شرح

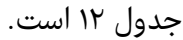

جدول |") نتايج حاصل از خوشه ينجم

\begin{tabular}{|c|c|}
\hline ارزش هارامتر در خوشه & 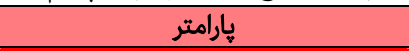 \\
\hline$\cdot$ & عامل تخمكگذارى \\
\hline \%१९/V & عامل مردانه \\
\hline 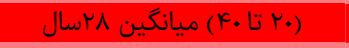 & سن \\
\hline$\cdot$ & $\mathrm{BMI}<\mathbf{M} / \Delta$ \\
\hline$\%$ & $\mid A / Q<B M I<Y F / Q$ \\
\hline$\%$ \% /Q & $r \Delta<B M I<r q / q$ \\
\hline$\% 1 . / 9$ & BMI $>\mu$. \\
\hline 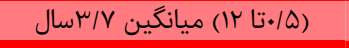 & طول نابارورى \\
\hline$\%$ & ن ابارورى اوليه \\
\hline$\cdot$ & نابارورى ثانويه \\
\hline 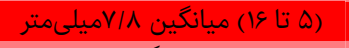 & ضخامت آندومتر \\
\hline 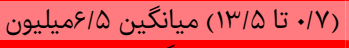 & تعداد اسيرم بعد از شستوشو \\
\hline 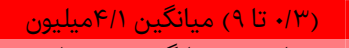 & تعداد اسيرمهاى نرمال بعد از شستوشو \\
\hline 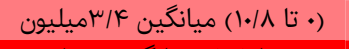 & تعداد اسيرمهاى FULL بعداز شستوشو \\
\hline 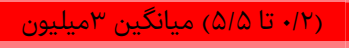 & تعداد اسيرمهاى كند بعد از شستوشو \\
\hline$\% r / r$ & Astheno Spermia \\
\hline \%१९/V & Terato Spermia \\
\hline$\% 1 / 1$ & Asterato Spermia \\
\hline
\end{tabular}

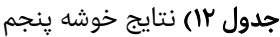

\begin{tabular}{|c|c|}
\hline ارزش بپارامتر در خوشه (\%) & لِارامتر \\
\hline ^१/• & عدم موفقيت \\
\hline $\mathrm{V} / \mathrm{I}$ & موفقيت \\
\hline$\mu / q$ & ن ن |مشخص \\
\hline
\end{tabular}

جدول سا) نتايج حاصله از خوشه ششم

\begin{tabular}{|c|c|}
\hline ارزش خارامتر در خوشه & "إرامتر \\
\hline$\% \Delta I / K$ & عامل تخمكگذارى \\
\hline$\% 9 r / 9$ & عامل مردانه \\
\hline (اب تا أF) ميانگين اساسال & \\
\hline$\cdot$ & $\mathrm{BMI}<1 \mathrm{~N} / \mathrm{Q}$ \\
\hline$\% 11 / 4$ & $\mid \mathrm{N} / \Delta<\mathrm{BMI}<Y F / 9$ \\
\hline$\% \vee k / \mu$ & $r \Delta<B M I<r q / 9$ \\
\hline$\% \mid F / \mu$ & BMI $>\mu$. \\
\hline (ه| •تا ||) ميانكين ساسال & طول نابارورى \\
\hline$\cdot$ & نابارورى اوليه \\
\hline$\% \mid .$. & نابارورى ثانويه \\
\hline 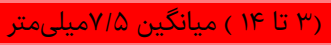 & ضخامت آندومتر \\
\hline 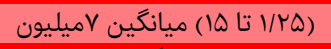 & تعداد اسيرم بعد از شستوشو \\
\hline 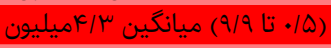 & تعداد اسيرمهاى نرمال بعد از شستوشو \\
\hline (• تا //.1) ميانكَين ع/سميليون & تعداد اسيرمهاى FULL بعد از \\
\hline 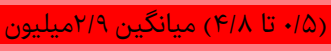 & تعداد اسيرمهاى كند بعد از شستوشو \\
\hline$\% \wedge / \Delta$ & Astheno Spermia \\
\hline$\% \wedge \Delta / \vee$ & Terato Spermia \\
\hline$\% 1 / 4$ & Oligo asterato.s \\
\hline$\% 1 / \mathbb{k}$ & Asterato Spermia \\
\hline$\% r / 9$ & Spermogram Normal \\
\hline
\end{tabular}

نتايج بهدستآمده از خوشه ششم نيز به شرح جدول سرا است.

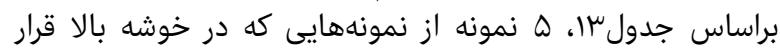

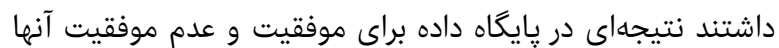

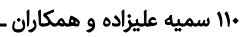
جدول V) نتايج حاصل از خوشه سوم

\begin{tabular}{|c|c|}
\hline ارزش پارامتر در خوشه & 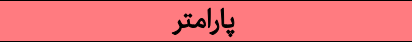 \\
\hline$\% \bowtie / \wedge$ & عامل تخمكگذارى \\
\hline$\% 1 .$. & عامل مردانه \\
\hline 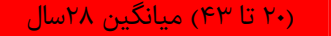 & 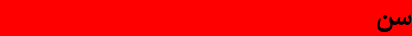 \\
\hline$\cdot$ & $B M I<1 / / D$ \\
\hline$\% F r / K$ & $M / \Delta<B M I<Y F / Q$ \\
\hline$\% \Delta$ & $r \Delta<B M I<r q / q$ \\
\hline$\% \mathrm{~V} / \mathrm{V}$ & BMI $>\mu$. \\
\hline (ا تا זIا) ميانكين ع/سال & طول نابارورى \\
\hline$\% § \Delta / K^{c}$ & نابارورى اوليه \\
\hline$\% \mu F / S$ & 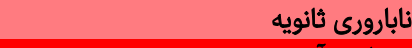 \\
\hline 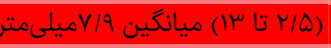 & ضخامت آندومتر \\
\hline 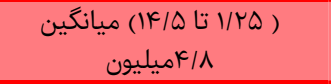 & تعداد اسيرم بعد از شستوشو \\
\hline 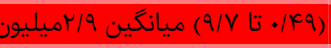 & تعداد اسيرمهاى نرمال بعد از شستوشو \\
\hline 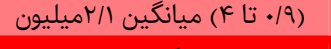 & تعداد اسيرمهاى FULL بعد از شستوشو \\
\hline (• تاع) ميانكين ه/Fميليون & تعداد اسيرمهاى كند بعد از شستوشو \\
\hline$\% 1 .$. & Terato Spermia \\
\hline
\end{tabular}

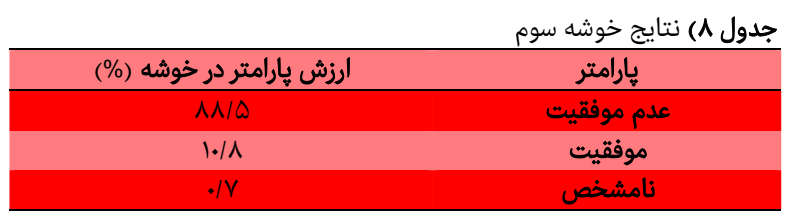

براساس جدول ^ متعداد ا نمونه از نمونههايى كه در خوشه بالا قرار

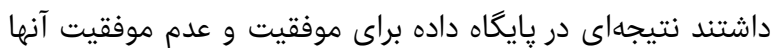

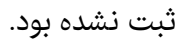
نتايج بهدستآمده از خوشه جههارم در جدول 9 و نتايج موفقيت و

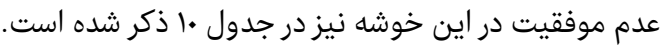

\begin{tabular}{|c|c|}
\hline ارزش پارامتر در خوشه & جدول 9) نتايج حاصل از خوشه جهارم \\
\hline$\% \wedge \Lambda / \wedge$ & عامل تخمكگذارى \\
\hline$\% k \cdot / V$ & عامل مردانه \\
\hline (19 تا r (k) ميانكين وrاسال & سن \\
\hline$\cdot$ & $\mathrm{BMI}<1 \mathrm{~N} / \mathrm{Q}$ \\
\hline$\% 1</ 1$ & $\mid \mathrm{A} / \Delta<\mathrm{BMI}<\mathrm{YF} / \mathrm{Q}$ \\
\hline$\% \vee / \mathbb{k}$ & $r \Delta<B M I<r q / q$ \\
\hline$\% \vee V / V$ & BMI $>\mu$. \\
\hline (ا تا \&1) ميانگين /هسال & طول نابارورى \\
\hline$\% \vee \cdot / k$ & نابارورى اوليه \\
\hline \% rq/द & نابارورى ثانويه \\
\hline 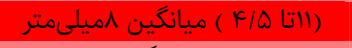 & ضخامت آندومتر \\
\hline 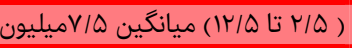 & تعداد اسيرم بعد از شستوشو \\
\hline 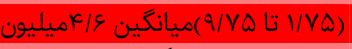 & تعداد اسيرمهاى نرمال بعد از شستوشو \\
\hline (• تا ץع/.|) ميانكين ه/Fاميليون & تعداد اسيرمهاى FULL بعد از شستوشو \\
\hline 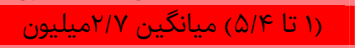 & تعداد اسيرمهاى كند بعد از شستوشو \\
\hline$\% \vee / \mathbb{K}$ & Terato Spermia \\
\hline$\%{ }^{\mu} \mathrm{V} /$. & Pyo spermia \\
\hline$\% \Delta \Delta / \Delta$ & Spermogram Norma \\
\hline
\end{tabular}

جدول •(1) نتايج خوشه جهارم (بارمتر

\begin{tabular}{|c|c|}
\hline ارزش هارامتر در خوشه & "ِارامتر \\
\hline$\wedge \Lambda / \wedge$ & عدم موفقيت \\
\hline $11 / 1$ & موفقيت \\
\hline - & نامشخص \\
\hline
\end{tabular}




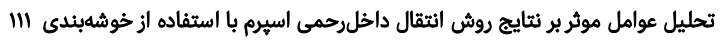

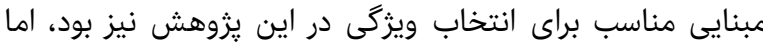

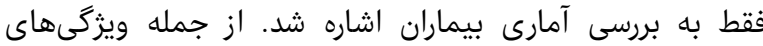

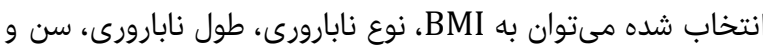

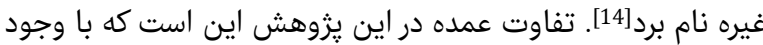

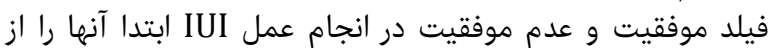

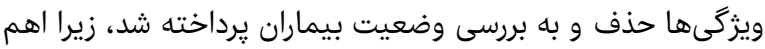

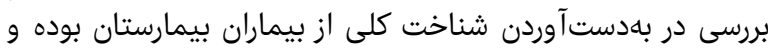

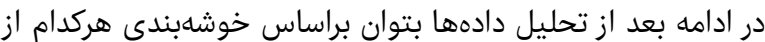

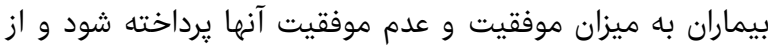

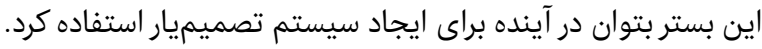

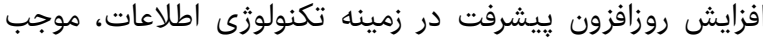

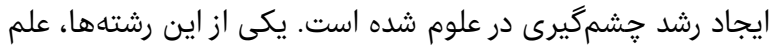

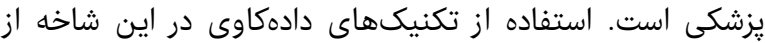

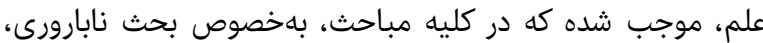

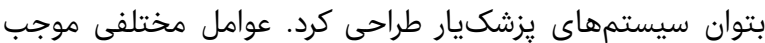

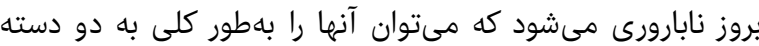

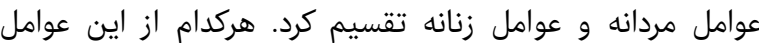

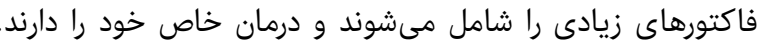

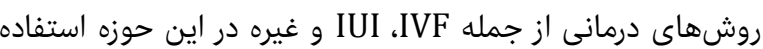

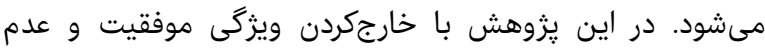

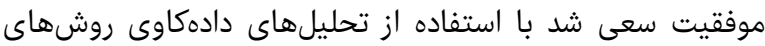

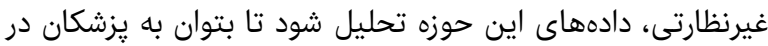

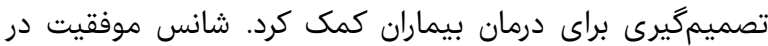

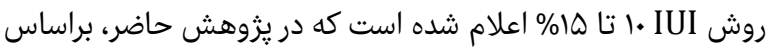

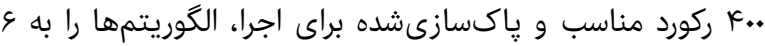

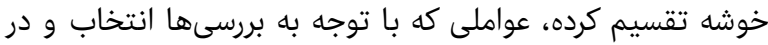

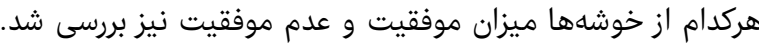

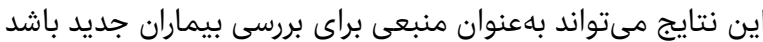

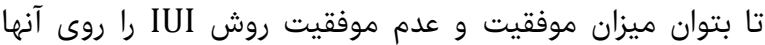

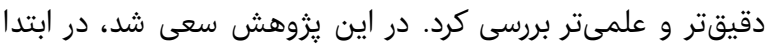

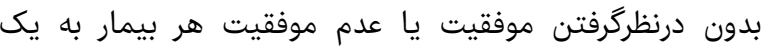

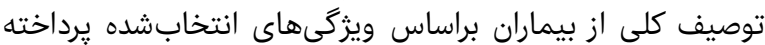

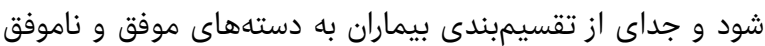

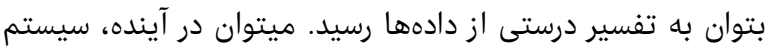

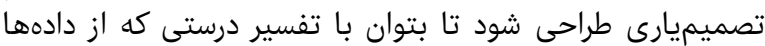

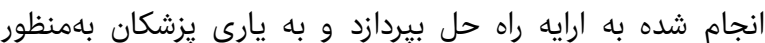
انتخاب درست روش درمان كمك كند.

عواملى مانند سن، حجم توده بدنى، نوع نابارورى، علت نابارورى و

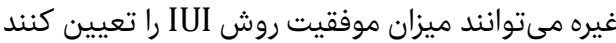

تشكر و قدردانى: از زحمات جناب آقاى دكتر صارمى رياست محترم

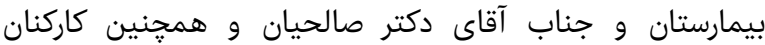
متخصص و با كفايت بيمارستان فوق تخصني

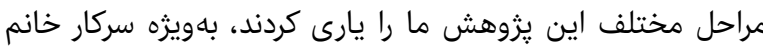

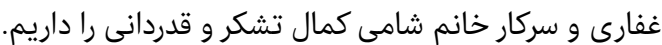

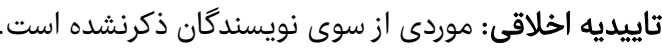

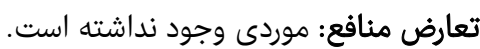

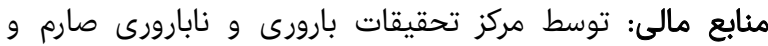
يزوهشكده سلولى- مولكولى و سلولهاى مالى بنيادى صارم تامين شده
ثبت نشده بود. نتايج موفقيت و عدم موفقيت در اين خوشه نيز در جدول با است.

جدول If) نتايج خوشه ششم (\%)

\begin{tabular}{|c|c|}
\hline ارزش پارامتر در خوشه & بارامتر \\
\hline$\Lambda \cdot /$ & عدم موفقيت \\
\hline $10 / \mu$ & موفقيت \\
\hline$k / V$ & نامشخص \\
\hline
\end{tabular}

براساس جدول \& ا تعداد \& نمونه از نمونههايى كه در خوشه بالا قرار

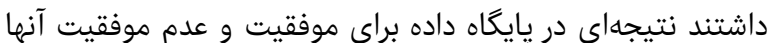
ثبت نشده بود.

بحث

يزوهشهاى زيادى با استفاده از الگوريتمهاى دادهكاوى در حوزه

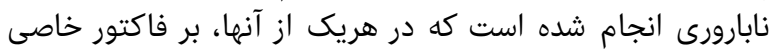
تمركز شده است. نمونههايى از فعاليتهاي اندامهام أنده در اين حوزه

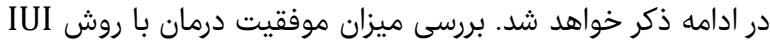

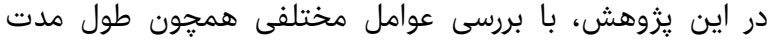

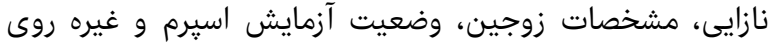
دادهها، به اين نتيجه رسيدند كه بهترين نتيجه درمانى براى نائ نازايى

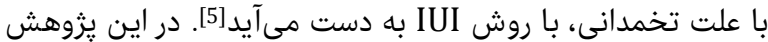

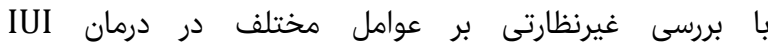

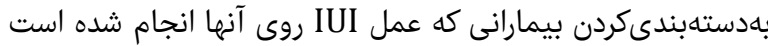

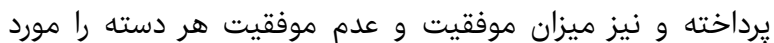

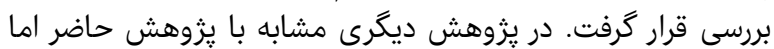

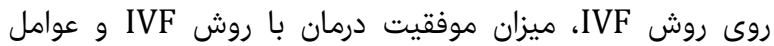

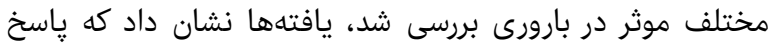

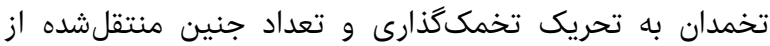

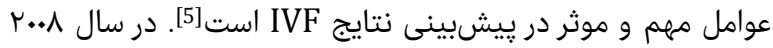

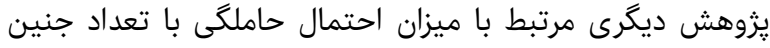

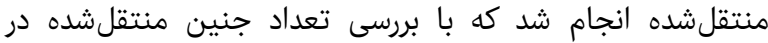

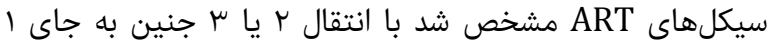

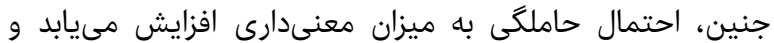

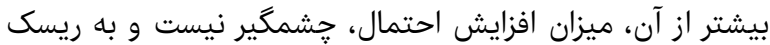

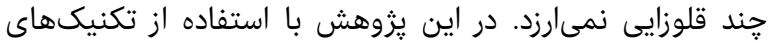

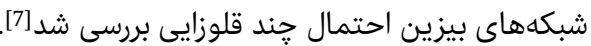

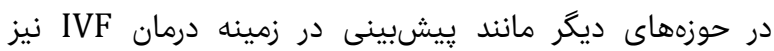

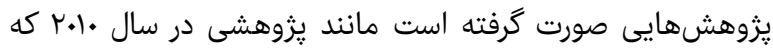

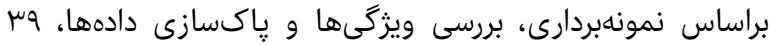

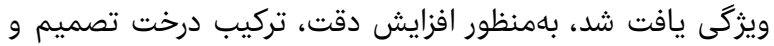

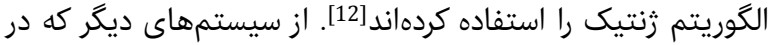

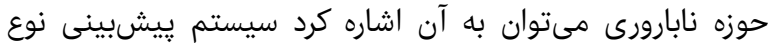
مناسب درمان IVF با استفاده از CBR است، إن اين سيستم

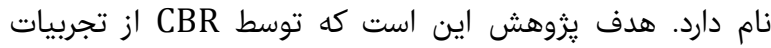

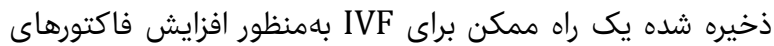

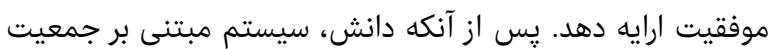

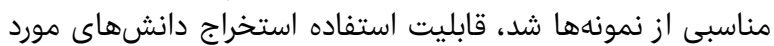

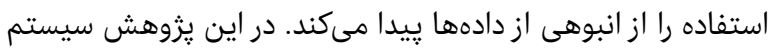

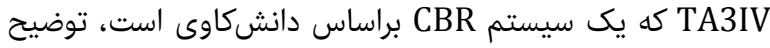

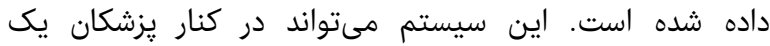

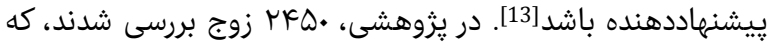


the selection of in vitro human embryos using morphological and clinical data. Comput Methods Programs Biomed. 2008;90(2):104-16.

7- Sohrabvand F, Shariat M, Fotoohi Ghiam N, Hashemi $M$. The relationship between number of transferred embryos and pregnancy rate in ART cycles. Tehran Univ Med J. 2009;67(2):132-6. [Persian]

8- Gazanfari M, Alizadeh S, Teimourpur B. Data Mining and Knowledge Discovery. Tehran: Iran University of Science and Industry Press; 2011.

9- Han L, Zhong Y, Huang B, Han L, Pan L, Xu X, et al. Sodium butyrate activates erythroid-specific 5aminolevulinate synthase gene through $\mathrm{Sp} 1$ elements at its promoter. Blood Cells Mol Dis. 2008;41(2):148-53.

10- Gonzalez T, Marggie D. A comparison in cluster validation techniques [Dissertation]. Puerto Rico: University of Puerto Rico; 2006.

11- Witten IH, Frank E, Hall M. Data Mining: Practical Machine Learning Tools and Techniques. Burlington: Morgan Kaufmann; 2011.

12- Guh RS, Wu TCJ, Weng SP. Integrating genetic algorithm and decision tree learning for assistance in predicting in vitro fertilization outcomes. Expert Syst Appl. 2011;38(4):4437-49.

13- Jurisica I, Mylopoulos J, Glasgow J, Shapiro H, Casper RF. Case-based reasoning in IVF: Prediction and knowledge mining. Artif Intell Med. 1998;12(1):1-24.

14- Cai Qf, Wan F, Huang R, Zhang HW. Factors predicting the cumulative outcome of IVF/ICSI treatment: A multivariable analysis of 2450 patients. Hum Reprod. 2011;26(9):2532-40.

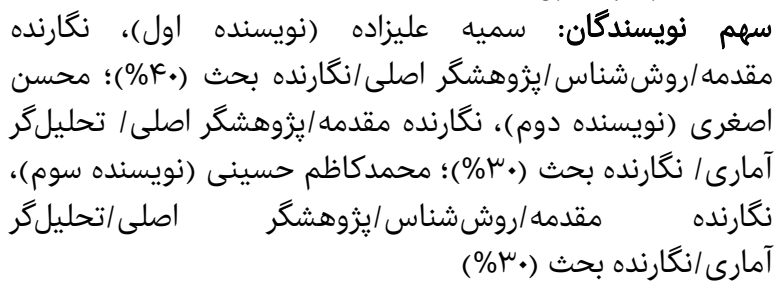

1- Chakrabarti S, Ester M, Fayyad U, Gehrke J, Han J, Morishita S, et al. Data Mining Curriculum: A Proposal (Version 1.0) [Internet]. London: The community for data mining, data science and analytics, SIGKDD; 1999. [updated 2006 Apr 30; cited 2007 Dec 14]. Avilable from: www.kdd.org/exploration_files/CURMay06.pdf.

2- Berry GT, Baker L, Kaplan FS, Witzleben CL. Diabeteslike renal glomerular disease in Fanconi-Bickel syndrome. Pediatr Nephrol. 1995;9(3):287-91.

3- Han J, Kamber M. Data Mining: Concepts and Techniques. 2th ed. Burlington: Morgan Kaufmann; 2011.

4- Saremi AT. Infertility Guideline. Tehran: Sarem Research Center; 2009. [Persian]

5- Vahid Roudsari F, Ayati S, Mirzaeeyan S, Shakeri MT, Akhtardel H. Fertility outcome after IVF and related factors. J Gorgan Univ Med Sci. 2009;11(3):42-6. [Persian]

6- Morales DA, Bengoetxea E, Larranaga P, Garcia M, Franco Y, Fresnada M, et al. Bayesian classification for 